\title{
Birch and Swinnerton-Dyer Conjecture Clay Institute Millenium Problem Solution
}

\author{
PAUL T E CUSACK* \\ Independent Researcher, BSc E, DULE, 1641 Sandy Point Rd, Saint John, NB, Canada E2K 5E8, Canada \\ *Corresponding Author: PAUL T E CUSACK, Independent Researcher, BSc E, DULE, 1641 Sandy \\ Point Rd, Saint John, NB, Canada E2K 5E8, Canada
}

\begin{abstract}
This paper presents the solution to the Birch Swimmerton problem. It entails the use of critical damping of a Mass-Spring-Dash Pod system which, when modelled mathematically, provide the equation that allows the solution of the zeta problem to be solved.
\end{abstract}

\section{INTRODUCTION}

But in special cases one can hope to say something. When the solutions are the points of an abelian variety, the Birch and Swinnerton-Dyer conjecture asserts that the size of the group of rational points is related to the behavior of an associated zeta function $\zeta(\mathrm{s})$ near the point $\mathrm{s}=1$. In particular this amazing conjecture asserts that if $\zeta(1)$ is equal to 0 , then there are an infinite number of rational points (solutions), and conversely, if $\zeta(1)$ is not equal to 0 , then there is only a finite number of such points.

\section{Equation OF Motion}

From Verruijt, we know the equation of motion for a mass -spring- dashpod system is:

$$
\mathrm{m} * \mathrm{~d} 2 \mathrm{u} / \mathrm{dt} 2+\mathrm{c} * \mathrm{du} / \mathrm{dt}+\mathrm{ku}=0
$$

So, taking the resonant frequency into account, the equation from Verruijt becomes:

$\mathrm{d} 2 \mathrm{u} / \mathrm{dt} 2+2 \mathrm{zw} 0 * \mathrm{du} / \mathrm{dt}+\mathrm{w} 02 \mathrm{u}=0$

Where $\mathrm{w} 0=$ resonant frequency and $\mathrm{z}$ is a measure of the system damping.

At critical damping, the characteristic equation is the golden mean function:

$\mathrm{x}-=1 /[\mathrm{x}-1]$

Or,

$\mathrm{x} 2-\mathrm{x}-1=0$

The roots to this equation are, of course, $-0.618,1.618$.

VALUE FOR i-the imaginary number

Now, before examining zeta $\mathrm{z}$ in equation form, we calculate a real value for the imaginary $\mathrm{i}=\operatorname{sqrt}(-1)$

$[1-\mathrm{i}]=1 /[(1-\mathrm{i})-1]$

$1-\mathrm{i}=1 /-\mathrm{i}$

$-\mathrm{i}=1 /[1-\mathrm{i}]$

$\mathrm{i}=1 /[\mathrm{i}-1]$

$\mathrm{x}=1 /[\mathrm{x}-1]$

$\mathrm{x}=-0.618,1.618$

International Journal of Scientific and Innovative Mathematical Research (IJSIMR) 
So, $\operatorname{sqrt}(-1)=-0.618,1.618$

DAMPING RATIO ZETA z

Now, zeta $=\mathrm{z}=$ damping ratio $=\mathrm{w} / \mathrm{w} 0$ :

$\mathrm{du} 0 / \mathrm{dw}=0: \mathrm{w} / \mathrm{w} 0=\sqrt{ }[1-2 \mathrm{z} 2]$

Algebraically:

$\mathrm{du} 0 / 0=\mathrm{dw}$

$\mathrm{w}=\mathrm{w} 0 * \operatorname{sqrt}[1-2 * \mathrm{z} 2]$

Taking the derivative:

$\mathrm{du} 0 / 0=\mathrm{dw}=\mathrm{w}^{\prime}=[\mathrm{w} 0 *(1-2 \mathrm{z} 2) 1 / 2]^{\prime}$

$\mathrm{w} 0 / 2 *(1-2 \mathrm{z} 2) 1.5] / 1.5$

In the Birch conjecture, there are two possibilities to consider. They are:

$\mathrm{z}(1)=0 \quad$ and $\quad \mathrm{z}(1)(\mathrm{not}=) 0$

In the first case:

$0=\mathrm{w} 0 / 3[(1-2(1) 2] 1.5$

$0=\mathrm{w} 0 / 3(11.5)$

$\mathrm{W} 0=0$

$\mathrm{Z}(1)=0, \mathrm{w} 0=0$

\section{CRITICAL DAMPING}

In the second case, we have critical damping. $\mathrm{z}(1)($ not $=) \mathrm{m} 0$

Say $\mathrm{z}(1)=1$

$1=\mathrm{w} 0 / 3[(1-2(12)] 1.5$

$\mathrm{w} 0=3$

Or $\mathrm{w} 0=\mathrm{C} 1 \quad \mathrm{w} 0$ is a real number.

In case 1 again:

$\mathrm{Z}(1)=0, \mathrm{w} 0=0$

$\mathrm{du} / \mathrm{dw}=0 \mathrm{w} / \mathrm{w} 0=\sqrt{ }[(1-2(\mathrm{z} 2)]$

$\mathrm{w} / 0=\operatorname{sqrt}[(1-2(\mathrm{z}) 2)]$

$\mathrm{w}=0$

$\mathrm{w} / \mathrm{w} 0=0 / 0$ Dividing by zero has infinite solution.

Now, finally, in the critical damping case:

$\mathrm{du} / \mathrm{dw}=0$

$\mathrm{w} / \mathrm{w} 0=\sqrt{ }[(1-2(\mathrm{z} 2))]$

$\mathrm{w} / \mathrm{C} 1=\sqrt{ }[(1-2(12))]$

$\mathrm{W}=\sqrt{ }(-1)(\mathrm{C} 1)$

We know sqrt(-1) is $=-0.618,1.618$

So, $\mathrm{w}=-0.618$ or 1.618

$\mathrm{w} / \mathrm{w} 0=0.618 \mathrm{C} 1 / \mathrm{C} 1=0.618$

Therefore there is a real solution to $\mathrm{z}$ at critical damping. 


\section{CONCLUSION}

Simple Mechanics combined with knowledge of the zeta function and the value of the imaginary number provide the ingredients to solve the Birch and Swinnerton-Dyer Conjecture.

\section{REFERENCES}

[1] AN INTRODUCTION TO SOIL DYNAMICS, A VERRIJUT SPRINGER

Citation: PAUL T E CUSACK, (2019). Birch and Swinnerton-Dyer Conjecture Clay Institute Millenium Problem Solution. International Journal of Scientific and Innovative Mathematical Research (IJSIMR), 7(11), pp. 12-14. http://dx.doi.org/ 10.20431/2347-3142.0711002

Copyright: (0) 2019 Authors, this is an open-access article distributed under the terms of the Creative Commons Attribution License, which permits unrestricted use, distribution, and reproduction in any medium, provided the original author and source are credited. 